\title{
CONDIÇÕES LIMITADORAS PARA A INTEGRALIDADE DO CUIDADO À CRIANÇA NA ATENÇÃO BÁSICA DE SAÚDE ${ }^{1}$
}

\author{
Francisca Georgina Macedo Sousa², Alacoque Lorenzini Erdmann², Elba Gomide Mochel ${ }^{4}$
}

\begin{abstract}
${ }^{1}$ Parte da tese - Tecendo a teia do cuidado à criança na Atenção Básica de Saúde: dos seus contornos ao encontro com a integralidade, apresentada ao Programa de Pós-Graduação em Enfermagem (PEN) da Universidade Federal de Santa Catarina (UFSC), 2008.

${ }^{2}$ Doutora em Enfermagem. Docente do Departamento de Enfermagem da Universidade Federal do Maranhão (UFMA). Coordenadora do Mestrado em Enfermagem da UFMA. Maranhão, Brasil. E-mail: fgeorginasousa@hotmail.com

${ }^{3}$ Doutora em Enfermagem. Docente do PEN/UFSC. Pesquisadora CNPq. Santa Catarina, Brasil. E-mail: alacoque@newsite. com.br

${ }^{4}$ Doutora em Enfermagem. Docente do Departamento de Enfermagem e do Mestrado Acadêmico em Enfermagem da UFMA. Maranhão, Brasil. E-mail: elbagmochel@hotmail.com
\end{abstract}

RESUMO: O cuidado integral à criança na Atenção Básica de Saúde sustenta-se no trabalho articulado e interativo entre equipe, família e comunidade. No entanto, esta proposta não tem sido operacionalizada no cotidiano das práticas de cuidado. Com isso, questionamos: que fatores limitam as práticas integrais de cuidado à criança? Objetiva-se compreender os fatores limitadores para a integralidade do cuidado à criança na atenção básica. Trata-se de estudo qualitativo apoiado pela Grounded Theory. Participaram do estudo 29 sujeitos, organizados em cinco grupos amostrais. Para a coleta de dados utilizou-se a entrevista semiestruturada. Neste manuscrito apresentase a categoria 'Traçando o caminho da integralidade, entre dificuldades' e as suas subcategorias. Conclui-se que os fatores limitadores para a integralidade do cuidado foram compreendidos a partir de estruturas políticas, institucionais, físicas e gerenciais, assim como aos aspectos profissionais e pessoais dos trabalhadores de saúde, que inclui o perfil, o processo de trabalho e os valores que estes escolhem para desenvolver as práticas de cuidado.

DESCRITORES: Enfermagem. Cuidado da criança. Cuidados primários de saúde.

\section{LIMITING CONDITIONS FOR INTREGAL CARE FOR A CHILD IN BRAZILIAN PRIMARY HEALTH CARE}

\begin{abstract}
Integral care for children in Primary Health Care sustains the articulated and interactive work between the team, family, and community. Nevertheless, this proposal has not been made operational through daily care practices. Thus, we asked which factors limit the practice of integral primary care for children and subsequently developed this qualitative study based on the Grounded Theory. Data was collected involving twenty-nine people in five sample groups, using semi-structured interviews. The category 'Outlining a path for integrality among difficulties' and its subcategories presented themselves. We conclude that limiting factors for the integrality of care were comprehended based on policy, institutional, physical, and managerial structures as well as professional and personal aspects among health care professionals, which includes the profile, the work process, and the principles chosen to develop care practices. DESCRIPTORS: Nursing. Child care. Primary health care.
\end{abstract}

\section{CONDICIONES LIMITADORAS PARA LA INTEGRALIDAD DEL CUIDADO A NIÑOS EN LA ATENCIÓN BASICA DE SALUD}

RESUMEN: El cuidado integral a los niños en la atención primaria de salud se sustenta en el trabajo articulado e interactivo entre el equipo, la familia y la comunidad. Sin embargo, esta propuesta no ha sido puesta en funcionamiento en la práctica diaria de la atención. Por eso nos preguntamos: ¿Qué factores limitan las prácticas integrales del cuidado al niño? El objetivo es comprender los factores que limitan la integralidad del cuidado a los niños en la atención primaria. Se trata de un estudio cualitativo con apoyo de la Teoría Fundamentada. El estudio incluyó a 29 sujetos, divididos en cinco grupos de la muestra. Para recoger los datos se utilizó la entrevista semi-estructurada. Se presenta la categoría: 'Trazando el camino de la integralidad entre las dificultades' y sus subcategorías. Se concluye que los factores que limitan la integralidad del cuidado son comprendidos a partir de estructuras políticas, institucionales, físicas, administrativas, así como los aspectos profesionales y personales de los trabajadores de la salud, que incluyen el perfil, el proceso de trabajo y los valores que ellos escogen para desarrollar las prácticas de cuidado.

DESCRIPTORES: Enfermería. Cuidado del niño. Atención primaria de salud. 


\section{INTRODUÇÃO}

O cuidado à criança na Atenção Básica de Saúde (ABS) busca a articulação e a interação do profissional na equipe, com as famílias e na comunidade para o desenvolvimento de ações que visam a cura, a reabilitação e a promoção da saúde. Esses objetivos embora claros, necessários e defendidos nas políticas brasileiras de atenção à criança não são tão fáceis de serem operacionalizados no cotidiano das Unidades Básicas de Saúde (UBS). Compreendemos que cuidar integralmente da criança na ABS é uma conjuntura com muitos ingredientes que ultrapassam a dimensão racional e assistencialista para alcançar as práticas relacionais $^{1}$ e subjetivas capazes de alterar vínculos dos profissionais com as mães, as famílias, a comunidade e com a própria equipe. Em um sentido mais amplo o cuidado caracteriza-se pelo compartilhamento, pelas trocas e pela reciprocidade de saberes, atitudes e práticas que se apresentam em um "movimento dinâmico e processual"1:72, com maior capacidade para resolver as situações/necessidades trazidas pelas demandas da saúde infantil. Compreende-se demanda o atendimento das necessidades trazidas pelas crianças e suas famílias e, não somente pelo número de crianças atendidas e de procedimentos realizados pelos profissionais nos turnos de trabalho. No entanto, pelo modelo de atenção ainda adotado, estas necessidades podem não estar sendo sequer identificadas. Este fato contrapõe-se à perspectiva da integralidade, onde o cuidado enquanto projeto terapêutico se efetiva pela cooperação, complementaridade e articulação das ações, saberes, atitudes e práticas de vários profissionais para a produção do trabalho em saúde. São contextos que pressupõe compartilhar e trocar informações configurando-se como ponto chave da comunicação nas relações interativas no e para o cuidado. ${ }^{2}$

Tendo estas afirmativas como suporte, questiona-se: Que fatores limitam as práticas integrais de cuidado à criança na Atenção Básica de Saúde?

\section{OBJETIVO}

Compreender os fatores limitadores para a integralidade do cuidado à criança na ABS.

\section{METODOLOGIA}

Estudo qualitativo apoiado nos pressupostos da Grounded Theory. ${ }^{3-4}$ A inclusão dos sujeitos de pesquisa foi guiada pela amostragem teórica, que consistiu em decidir quais dados coletar e onde encontrá-los como definido no referencial metodológico da Grounded Theory. Significou escolher locais e pessoas com o objetivo de desenvolver os conceitos na proporção que estes iam sendo construídos. Dessa maneira, a amostragem foi se constituindo a partir da combinação de conceitos aliados à sensibilidade das investigadoras para perceber as lacunas que ainda necessitavam ser esclarecidas. Colocamo-nos na busca de grupos de pessoas, que nos ajudaram na construção das categorias e no refinamento das mesmas. O número de participantes e os respectivos grupos amostrais foram se configurando a partir da análise dos dados e das reflexões sobre as categorias construídas. Por compreender que o objeto investigado encontrava-se situado sob três grandes dimensões: da política de saúde, da organização do sistema de saúde e da organização das práticas de cuidado, procuramos buscar, nestas três dimensões, os participantes da investigação, que representassem melhores possibilidades para a compreensão da integralidade do cuidado a criança na ABS. Assim, para o primeiro grupo amostral, centramos a investigação na primeira e segunda dimensões, do qual participaram o gestor estadual e o municipal de saúde, os coordenadores e chefes de serviços da ABS, totalizando sete participantes. Participaram do segundo grupo amostral os profissionais que, no período da coleta, exerciam função de coordenadores de curso de graduação (Enfermagem e Medicina); coordenadores de curso de pós-graduação (Especialização em Saúde da Família e Mestrado em Saúde da Mulher e da Criança) e docentes da graduação, totalizando seis participantes. O terceiro grupo amostral envolveu sete profissionais do Programa Saúde da Família (PSF) (cinco enfermeiros e dois médicos). Para este grupo, foram definidos critérios de inclusão: ser Unidade Saúde da Família, estar com a equipe completa e os profissionais terem vínculo definido por concurso público e em exercício profissional por pelos menos um ano na equipe. O quarto grupo amostral foi constituído por cinco médicos do PSF, para os quais foram estabelecidos os mesmos critérios do grupo anterior. O quinto grupo amostral foi composto por quatro mães, cujas famílias eram cadastradas no PSF e as crianças acompanhadas pela equipe da Unidades de Saúde da Família (USF). Participaram, portanto, 29 sujeitos entre profissionais de saúde e mães de 10 equipes da Estratégia Saúde da Família.

A coleta de dados foi realizada no período de outubro de 2006 a maio de 2007. Como instrumento de coleta de dados foi utilizada a entrevista 
semi-estruturada realizadas nos locais de trabalho dos participantes, em data e horário por eles determinados. A preocupação era disponibilizar um local tranquilo, de pouco ruído e com menor possibilidade de interrupções, o que foi prontamente providenciado pelos participantes do estudo. As entrevistas foram gravadas em meio digital e transcritas logo após terem sido realizadas. O rigor na transcrição exigiu atenção minuciosa, no sentido de apresentar as experiências e significados atribuídos pelos participantes na sua forma original.

A análise dos dados seguiu as etapas da codificação aberta, axial e sistemática. O primeiro passo da análise consistiu na codificação das entrevistas, processo que se dá pela quebra dos dados brutos em pequenos pedaços denominados de códigos. Esta etapa é denominada de codificação aberta e tem por objetivo a redução dos dados. Nessa etapa os códigos foram avaliados por similaridades e diferenças, desenvolvendo um segundo agrupamento tendo como objetivo a configuração inicial das categorias. Os códigos, por um processo de comparação, deram origem a categorias (codificação axial). As categorias foram reorganizadas por meio das conexões entre elas de forma a reduzi-las e uni-las em um significado comum ou fenômeno (análise seletiva).

Seguindo os critérios éticos, definidos na Resolução 196/96, do Conselho Nacional de Saúde, somente iniciamos a coleta de dados após aprovação no Comitê de Ética do Hospital Universitário - HUUFMA sob número 254/06. A adesão, tanto dos profissionais, quanto das mães foi voluntária, independente de qualquer benefício ou constrangimento. A coleta dos dados foi posterior aos esclarecimentos sobre os objetivos do estudo e da leitura e assinatura do Termo de Consentimento Livre e Esclarecido. Para garantir o sigilo na identificação dos participantes foi atribuída a letra E seguida pelo número da entrevista $(1,2,3 \ldots)$ após cada fragmento das falas.

Apresenta-se neste manuscrito a categoria "Traçando o caminho da integralidade, entre dificuldades" como um dos conceitos construídos na tese de Doutorado em Enfermagem, defendida em um Programa de Pós-Graduação da região sul do Brasil, cuja investigação apresenta uma teoria substantiva sobre a atenção à criança na $\mathrm{ABS}$, na perspectiva da integralidade. ${ }^{5}$ A categoria "Traçando o caminho da integralidade, entre dificuldades" foi definida como estratégia interveniente desse constructo teórico. Na Grounded Theory a categoria que representa estratégia interveniente é aquela que altera o impacto das condições causais no fenômeno, podem facilitar, dificultar ou restringir as estratégias.

\section{RESULTADOS E DISCUSSÃO}

Traçando o caminho da integralidade entre dificuldades é uma categoria delimitada pelas seguintes subcategorias: Identificando Conflitos, Delineando o trabalho na ausência do encontro; Sentindo insegurança; Lidando com a falta de estrutura das unidades de saúde; Falando da ineficácia do sistema de referência e contra-referência.

Identificando Conflitos - ao planejamento e a gestão do cuidado no processo saúde-doença caberá lidar com a racionalidade técnico-científica e, ao mesmo tempo, com as dificuldades geradas pelas competências, autoridades, autonomias e poderes de cada profissional. Portanto, pensar a integralidade do cuidado à criança pelo trabalho interdisciplinar e em equipe é pensar na diversidade, nos processos de interação, nos conflitos e nas contradições. Para os participantes da investigação os conflitos decorrem da diversidade de opiniões e posturas dos profissionais frente às competências e à colaboração de cada um no enfrentamento de situações de cuidado à criança. Há um embate entre complementaridade, ampliação da autonomia e competição dos profissionais como revelado na fala:

[...] não tem a ver com criança, mas só pra te ilustrar como as coisas não estão nos trilhos: outro dia entrou aqui no consultório um senhor, já conhecido nosso, da equipe, ele é hipertenso, diabético e naquele dia não estava se sentindo bem, ele me disse que estava sem tomar o remédio [...]. Eu precisava saber como estava a glicemia. Pedi que ele fosse até a sala da enfermeira pra fazer e voltasse. Foi um Deus nos acuda. Ela veio de lá que nem um furacão. Disse que estava ocupada, que tinha gestantes pra atender, que se eu não podia fazer a glicemia que ela também não podia. Qual o problema da enfermeira ter feito a glicemia? Não podemos pensar que essa era uma atividade complementar e que tanto ela, como eu ou a auxiliar de enfermagem poderia fazer? Mas a forma como o serviço se organizou, essa atividade não é pra ser feita pelo médico porque tudo aqui fica na sala da enfermeira. [...] os atritos existem porque eu acho que estamos perdidos sem saber muito bem o que fazer ou como fazer (E 1).

Identificando conflitos como subcategoria revela a dificuldade em um profissional complementar o cuidado do outro, causada muitas 
vezes, pela baixa interação entre os membros da equipe. ${ }^{6}$ A tensão surge do embate entre a complementaridade e interdependência dos profissionais nas atividades e práticas do cuidado. A complementaridade surge como uma questão/ problema no cotidiano do trabalho. Todavia, o requerido para a eficácia e eficiência dos serviços seria a autonomia técnica aliada à articulação de ações. ${ }^{7}$ Foi uma categoria que suscitou situações que devem produzir a necessária discussão não só de papéis - quem faz o quê -, mas de refletir e problematizar os modos de produzir cuidados quer sejam pelo enfermeiro, pelo médico ou pelo Agente Comunitário de Saúde. É preciso investir em alterar o modo de produzir o cuidado, afinal o profissional tem a autonomia para imprimir mudanças no processo de trabalho.

Delineando o trabalho na ausência do encontro - reafirmando o já dito, o cuidado como projeto terapêutico se efetiva pela cooperação, complementaridade e articulação das ações com conexão para a produção do trabalho em saúde. Mas, o trabalho onde há ausência do encontro entre os profissionais e destes com as crianças e suas famílias caracteriza-se pela ausência do processo de comunicação e funciona como barreira para a construção de novas formas de produzir o cuidado na perspectiva da integralidade. Esta subcategoria diz respeito, a ausência do encontro dos profissionais da mesma equipe nos mesmos turnos de trabalho. No município onde a pesquisa foi desenvolvida, a carga horária é organizada por turnos de trabalho totalizando sete turnos por semana. Dessa forma os profissionais, a partir das suas disponibilidades, organizam seus horários muitas vezes divergentes entre eles mesmos. As falas explicam como os profissionais se organizam para isso:

Fazemos sete turnos de trabalho e as vezes não coincide o turno do médico com o da enfermeira. Todo mundo tem outros empregos o que torna difícil estarem todos nos mesmos turnos. Nos organizamos procurando cobrir todos os horários e garantir o atendimento da população. Mas em um ou outro turno pode estar o médico e não a enfermeira ou o contrário (E5).

Se você vai na Unidade só encontra um profissional, ou o médico ou a enfermeira. Ao invés dos dois estarem trabalhando juntos, o que fazem? Um fica em um período e o outro no outro. Isso são questões que vão sendo permitidas no processo de trabalho. Por outro lado, os gestores aceitam, são coniventes. O resultado disso tudo é que não há um trabalho de equipe. O que possibilita o trabalho em equipe é fazer com que as pessoas se encontrem. Era preciso que os profissionais estivessem juntos no trabalho (E2).

Tenho consciência de que isso gera uma demanda maior nos dias de atendimento, porque tenho que atender a mesma quantidade em menos dias. Isso é geral. Aqui em São Luís ainda é melhor se a gente compara com os horários que os colegas estão fazendo no interior do estado (E20).

Isto tem gerado um descompasso/desencontro entre os objetivos do Programa Saúde da Família (PSF) e a organização do trabalho pelos profissionais de saúde. A redução da carga horária restrita a turnos pode acarretar maior número de atendimentos, pois a redução dos dias de trabalho não significa redução da demanda. A consequência imediata dessa condição são atendimentos caracterizados pelo distanciamento, orientados pela queixa da doença e por uma escuta comprometida que torna o atendimento ineficaz e de baixa resolução. Pelo desencontro dos profissionais são relatadas algumas experiências vivenciadas pelo enfermeiro e pelas mães, que implicam em situações difíceis no atendimento à criança na atenção básica:

O difícil são as situações em que a criança chega com um problema mais sério na unidade, eu fico sem poder fazer muito pela ausência do médico. Outro dia fiquei aqui com uma criança que chegou com uma dispnéia, coloquei a nebulização, repetimos a nebulização e a criança não melhorava e a gente ficava assim no desespero olhando pra mãe, olhando pra criança [...] eu acredito que se estivéssemos juntos nos mesmos horários esses momentos seriam menos estressantes (E18).

Aqui é assim, tem dia que tem médico, tem dia que não tem, e a gente fica sem saber quando tem. Então quando os meninos têm uma coisa assim que precisa de remédio eu levo direto pro hospital, nem vou perder tempo no posto (E27).

Sentindo Insegurança - é o sentimento revelado por mães e enfermeiras no cuidado à criança nos serviços de saúde da atenção básica que decore pela ausência do encontro entre profissionais de saúde da mesma equipe e pela não complementaridade das ações profissionais. As enfermeiras relatam que tomar decisões na ausência do médico envolve, muitas vezes, tensão e desgaste, enquanto as mães buscam atendimento aos filhos nos serviços de urgência quando estes deveriam ser atendidos na ABS. As mães procuram a ABS quando seus filhos necessitam de avaliação do crescimento e do desenvolvimento, para atualizar o calendário básico de vacinação, nas situações 
em que seus filhos apresentam queixas de febre, tosse ou diarréia ou para providenciar requisição de exames de rotina. Os casos de "doenças" que consideram mais graves procuram o serviço de urgência, pois se sentem inseguras em relação ao atendimento da unidade básica de saúde. A possibilidade de não encontrar o médico na unidade ou ainda por considerar que estes não estão capacitados para o atendimento à criança doente são motivos da insegurança das mães:

[...] às vezes o médico não vem e a gente fica aqui esperando. Eu já fiquei aqui uma manhã quase toda e o médico não veio. E a tarde aqui nunca têm médico eles vêm pra cá mais é de manhã. Tem vez que dá certo, tem vez que eu já levo direto pro Hospital porque a gente que é mãe não quer ver um filho da gente doente sem fazer nada. Já teve vez que eu sai daqui chorando, porque a enfermeira me disse que não podia fazer nada, porque não tinha médico no Posto. Aí a gente tem de arrumar dinheiro para a passagem e levar para o Hospital. Aí quando a gente chega lá a doutora pergunta se não tem médico perto da casa da gente. Outro dia eu tive de brigar com uma doutora. Disse que eu só tava ali porque o doutor não vai para o posto e porque não tem remédio (E28).

Na urgência é mais seguro, porque aqui nem todo dia tem médico. Se for uma coisa mais grave eu não espero. Uma coisa simples eu venho aqui, mas uma coisa mais grave eu vou para o hospital. Porque quando a gente vem aqui não tem médico, não tem remédio e mesmo quando têm eles mandam a gente levar pro Hospital. Então assim eu vou logo. É mais seguro. Ele vem aqui todo mês pra saber do peso, pra medir, pra tomar as vacinas, essas coisas assim (E25).

Outro dia meu filho estava com febre muito alta, ele ficava todo se tremendo e aí eu trouxe aqui e o médico passou um remédio, um antibiótico. Ele não melhorou aí eu levei lá no Hospital, na urgência, a doutora de lá me disse que o remédio tava errado, que não servia para criança. Aí a gente fica com medo de trazer e o médico daqui passar o remédio errado. É porque os médicos daqui não são pediatras, e não sabem passar remédio pra criança [...] assim que a doutora falou e aí eu fiquei com medo. O povo diz muito que os médicos daqui não sabem consultar criança porque eles são clínicos gerais, é assim que o povo diz. Eu levo logo pro hospital porque é mais seguro (E29).

O PSF se sustenta pela argumentação de que o modelo hegemônico centrado na doença e no hospital é pouco eficiente e pouco resolutivo.
Ainda que de forma excludente e centrado na doença, o modelo médico-centrado ainda demonstra credibilidade frente às demandas de agravos à saúde pelos quais são acometidas as crianças. Por outro lado, as dificuldades apontadas nas falas sugerem que a organização e a estrutura do PSF necessitam ser repensadas. O Brasil apesar das mudanças no perfil etário da população ainda se configura como um país jovem. No nordeste essa realidade é muito mais forte e, em São Luís a população de crianças de zero a nove anos é a terceira maior segundo dados do Ministério da Saúde. Isto representa um percentual de $19,2 \%$ da população total. ${ }^{8}$ Estes dados somadas às especificidades do atendimento pediátrico e ao direito da criança à assistência especializada mobilizaram a Sociedade Brasileira de Pediatria (SBP) a propor a inclusão do pediatra no PSF. Alegam que as mães consideram importante a presença desta especialidade no PSF e, que as mesmas, pouco acreditam naqueles que não o pediatra para o atendimento dos seus filhos. A SBP apóia a reivindicação na assertiva de que a atenção básica precisa ter elevado grau de resolução de problemas de saúde da criança e que esta não pode ser superficial quando estão em jogo as necessidades fundamentais da criança e do adolescente. A ABS requer qualidade profissional para atuar no vasto campo do conhecimento da pediatria e o PSF reforça a discriminação da classe social pobre excluindo o direito da criança ser assistida pelo pediatra. ${ }^{9}$ Sentindo insegurança revela as dificuldades no atendimento à criança $\mathrm{e}$ foram expressas pelos profissionais conforme as falas abaixo:

Somos três pediatras, eu e dois que são das outras equipes e um colega que é cirurgião e que às vezes me pede para atender as crianças da área dele. Os colegas que não são pediatras têm dificuldades em atender a criança. Eu acho que a pediatria é muito específica. É mais fácil o pediatra atender o adulto, a mulher do que o clínico atender a criança. E isso é difícil porque as mulheres e as crianças são quem mais procuram a unidade. Eu me sinto um pouco dividida no PSF tendo que atender a todas as faixas etárias, todos os problemas de saúde (E12).

Aqui no PSF tem de tudo. Nós temos o clínico, o cirurgião, o obstetra e o pediatra, o recém formado e aqueles que já aposentaram e que voltaram a ativa. O problema é que os colegas não se sentem seguros em atender as crianças e aí acontecem duas coisas: ou eles desvalorizam a clínica da criança e não fazem um diagnóstico adequado ou por insegurança 
encaminham todos os casos para as emergências. Ainda há dificuldades na prescrição dos medicamentos, em prescrever a dose correta (E9).

São relatos coerentes com as falas das mães e com as reivindicações. São vozes que tendem a ser ouvidas pelos movimentos de mudanças já discutidos na composição e organização das equipes do PSF.

Lidando com a falta de estrutura das unidades de saúde - as mudanças propostas para o novo modelo assistencial necessitam de uma adequada infra-estrutura física para garantir a eficiência na prestação de serviços e assim reafirmar o compromisso do SUS com a comunidade. Sob esse raciocínio a Unidade de Saúde da Família se constitui como referência para o primeiro contato do usuário com o sistema de saúde. Portanto, é necessário dispor de recursos físicos e estruturais compatíveis com esta proposta e com a ação dos profissionais de saúde em relação a esse compromisso. No entanto, trabalhando no PSF os profissionais e mães experimentam os desafios da falta de estrutura física das unidades para o cuidado à criança. Os profissionais criticam a estrutura física das unidades e reclamam por melhores condições assim como a disponibilidade de materiais, equipamentos e/ou instrumentos fundamentais à realização do trabalho conforme descrito nos fragmentos das falas dos participantes:

A nossa unidade foi adaptada, era uma residência, ela é pequena, nós temos problema com iluminação, as salas são escuras, não tem janelas, ventilação e é muito quente. As salas estão assim improvisadas, fazemos nebulização nesse cantinho aqui que é escuro, quente e sem ventilação. Não é um espaço adequado. Ficamos mais cansados porque é quente e quando todos os profissionais das duas equipes estão na unidade é terrível, porque a unidade fica lotada, as crianças choram, as mães reclamam. Eu tenho certeza que isso interfere no nosso rendimento e na qualidade dos nossos atendimentos (E14).

O PSF é isso aqui. Muita gente para atender e nenhuma condição. Falta água pra lavar a mão. As condições de trabalho são muito ruins (E11).

Olha só essa unidade. A estrutura é péssima, isso aqui era uma residência de pessoas humildes e que foi alugada pela secretaria para funcionar uma unidade de saúde. A única coisa que fizeram foi colocar essas divisórias e pintar. É insuportável o calor. Não tem iluminação, não tem ventilação. Não temos um banheiro digno pra usar. Isso aqui só é assim porque foi pensado para atender a população pobre. Eu quando saio daqui estou exausta, cansada não pelo trabalho em si, mas pelas condições em que estou trabalhando. Que exemplo estamos dando para esse povo todo? Orientamos que a casa precisa ser ventilada, arejada, iluminada e o que eles vêem aqui, é isso, é igual ou até pior que muitas casas dos moradores dessa área. A secretaria reproduz a miséria dessa população. [...] Não temos suporte pra fazer sequer a parte educativa. Se fazemos uma reunião, 10 minutos depois fica todo mundo se sacudindo, se abanando, ninguém presta mais atenção a nada de tanto calor (E15).

Tem dia que a gente fica aqui e o menino dorme, acorda, chora. Aqui é muito quente e com esse tanto de criança fica muito ruim. Eu fico lá fora porque tem as doenças aqui dentro, tem menino tossindo, com problema que passa de uma pessoa pra outra. Então eu tenho medo da gente chegar com uma coisa e o filho da gente sair daqui com duas (E28).

O ambiente físico do trabalho deve aliar funcionalidade, acolhimento e conforto relacionados, em especial, aos aspectos de iluminação, ventilação e áreas de circulação. O Ministério da Saúde ${ }^{10}$ define que os espaços das USF devem ser adequados à realidade local, ao quantitativo da população adstrita, à sua especificidade, ao número de usuários esperados para atendimento e ao número de equipes de saúde da família previstas para a unidade. Dessa forma a estrutura de algumas unidades de saúde da família apresenta-se contrária às definições estruturais e físicas estabelecidas pelo Ministério. Lidando com a falta de estrutura das unidades de saúde diz respeito também à falta de material de consumo com destaque aos medicamentos. Diariamente profissionais e mães deparam-se com a falta de medicação básica para a atenção à criança, o que motiva e faz aumentar o número de encaminhamentos de crianças para os serviços de urgência da capital. Isto acarreta baixa resolutividade e gera descontentamento e insegurança de profissionais e mães. Nas falas dos participantes o cuidado à criança é prejudicado pela falta de recursos materiais e de medicamentos:

Sem contar que por várias vezes falta remédio, até paracetamol, até termômetro falta aqui. Falta remédio, falta até o soro oral, não tem antibiótico (E15).

[...] avaliar o crescimento, orientar a vacinação, podemos orientar a amamentação. Essa parte nós fazemos direitinho. Quer ver tudo isso ir por água abaixo é só aparecer uma criança com febre. 
Eu não resolvo a febre da criança. Uma criança é encaminhada para um serviço de urgência porque aqui não tem paracetamol, por incrível que pareça, outro dia nem água tinha pra fazer uma compressa pra baixar a febre de uma criança. Eu tive de tirar dinheiro do meu bolso pra comprar paracetamol (E11).

[...] a enfermeira me disse que não podia fazer nada porque não tinha remédio no Posto. Eu tenho vergonha de dizer que na minha casa não tem comida. A gente tem vergonha, mas aqui, eles dizem mesmo que não tem remédio e não tem vergonha. [...] um hospital sem remédio, sem médico, não é hospital. Aí a gente tem de arrumar dinheiro para a passagem e levar o filho da gente para o Hospital [...] (E24).

$\mathrm{Eu}$ ando sempre com paracetamol na bolsa porque muitas vezes não tem no posto. A gente tem que trabalhar mesmo na falta dessas coisas (E9).

[...] A falta de medicação é um problema. Ontem mesmo atendi uma criança com $39^{\circ} \mathrm{C}$ de febre e no Posto não tinha medicação. Eu é que tinha na minha bolsa. Os profissionais têm sempre que "arranjar" as coisas. Se eu não tivesse o remédio, a mãe dessa criança teria de ir para uma urgência só para tomar remédio de febre. Isso é um problema. Às vezes ficamos de mãos atadas. E quando chegamos nas urgências estão todas lotadas, eu fico horrorizada, é criança em maca, em cadeira, em banco, outro tanto esperando na porta com coisas que poderiam ter sido resolvido na Atenção Básica. Só que na Atenção Básica falta também estrutura. Falta resolutividade (E14).

Mesmo garantido em lei, o Estado (União, Estados e Municípios) apresenta dificuldades em garantir recursos suficientes e gerenciamento adequado para efetivar o direito à saúde como definido na Constituição Federal de 88. A insuficiência de recursos constitui-se em um limite real no cotidiano dos serviços o que faz com que a produção da saúde seja tarefa difícil. A baixa capacidade técnica e financeira dos municípios e sua crescente responsabilização quanto à implementação de programas e políticas de saúde trazem em si um conjunto considerável de riscos e incertezas. ${ }^{11} \mathrm{Os}$ profissionais não têm conseguido resolver os problemas de saúde da criança por dificuldades físicas e estruturais das unidades de saúde e pela falta de medicamentos. São situações que fazem aumentar o número de encaminhamentos da criança para os níveis secundários e terciários de saúde.

Falando da ineficácia do sistema de referência e contra-referência - a não articulação entre os diferentes níveis da atenção caracteriza mais uma dificuldade no cuidado integral à criança na ABS. Gestores, enfermeiros, médicos da ABS e mães apontam que as principais dificuldades dizem respeito à difícil disponibilização de recursos diagnósticos e de suporte terapêutico para as crianças com destaque para aquelas com doenças crônicas e/ ou metabólicas. Há também nos relatos dificuldades na resolutividade de casos rotineiros como febre, pneumonias e exames de rotina. São situações que revelaram o sistema de referência e contra-referência como uma problemática na organização do sistema e nas ações de cuidado à criança na ABS. O acesso universal a serviços resolutivos e eficazes parece não estar configurado nas Unidades de Saúde da Família. Os aspectos que nos permitem dirigir esse comentário são os que estão presentes nos seguintes fragmentos de falas:

[...] Considero importante a questão da continuidade da assistência que vai da consulta de rotina, aos exames inclusive aos exames mais especializados quando forem necessários. Temos crianças com intolerância alimentar que é um problema cada dia mais freqüente, mas não temos estrutura para esses casos. Desde o mais simples exame demora não sei quanto tempo e enquanto isso ficamos sem condições de fechar o diagnóstico. Se você tem dúvidas quanto ao diagnóstico e solicita apoio de um gastro, passa quatro a cinco meses para a mãe conseguir a consulta com o especialista [...]. Estamos buscando resolver as coisas naquela coisa do amigo. Estamos tentando resolver as coisas dessa forma porque não existe um fluxo dessa criança em todos os níveis de complexidade do serviço de saúde. Existe um fluxo que é burocrático, que é o do papel, mas ele não funciona por si só, é preciso que nós profissionais fiquemos aqui pedindo, pedindo, ligando. $\mathrm{O}$ fluxo não funciona de forma espontânea, ele não acontece (E5).

Quando precisamos encaminhar crianças para o hospital ou porque não tem remédio naquele momento, naquele dia ou porque o caso realmente é grave e necessita de internação. É o 'fluxo do amigo': a gente liga antes e diz que vai encaminhar uma criança assim e assim, ou a gente acompanha a criança e a mãe. Vamos até com o jaleco do PSF na tentativa de garantir o atendimento na referência (E16).

Temos crianças com sequelas neurológicas, em famílias humildes, sem suporte nenhum sequer pra levar a criança a um serviço de fisioterapia. A mãe não consegue manter o programa de fi- 
sioterapia porque o acesso a isso ainda é difícil. Tenho crianças aqui que poderiam não ter tantas limitações, mas por falta de um apoio terapêutico e social elas ficam em casa sem condições de serem estimuladas, mofando numa rede, numa cadeira de roda improvisada, isso é muito difícil (E18).

[...] quando se fala em referência e contra-referência me lembra aqueles primórdios quando se discutia o SUS. Estou falando dos anos 84/85 e, por incrível que pareça tantos anos depois isso ainda não acontece de uma forma eficaz. O que se observa, é que quando uma criança é encaminhada não é por um fluxo normal, mas pelo profissional conhecer um outro na média e na alta complexidade. E a contra-referência, isso é que é mais complicado ainda, porque não vemos isso acontecer de uma forma formalizada, oficializada, de rotina nos serviços (E2).

Quando os meninos adoecem eu vou logo pra urgência porque lá ele já toma o remédio, se precisar fazer exame faz tudo, as vezes eu peço para fazer logo os exames porque aqui no posto é mais difícil. Lá é mais fácil, por isso eu vou logo pra lá (E27).

A integralidade como princípio doutrinário do SUS deve considerar as necessidades específicas das crianças inserindo-as em uma rede hierarquizada da atenção em saúde com níveis crescentes de complexidade dos serviços. Assim as ações de baixa, média e alta complexidade buscam articular-se para aumentar o nível de resolutividade e de sua capacidade no atendimento às demandas. Observamos tanto nas falas dos gestores como dos profissionais a inexistência de uma rede articulada dos serviços de atenção à criança. O sistema de saúde não garante efetividade do sistema de referência e contra-referência, apresentando, portanto, problemas por não garantir continuidade do cuidado nos diversos níveis da atenção.

\section{CONSIDERAÇÕES FINAIS}

Vários foram os fatores que se constituíram como limitadores para a integralidade do cuidado à criança na Atenção Básica de Saúde. Alguns políticos e gerenciais, outros institucionais e estruturais das unidades de saúde. Dentre os fatores políticos e gerenciais destaca-se a insuficiência de recursos para a saúde e para o cuidado à criança na ABS, a falta de insumos, em especial, de medicamentos, assim como os aspectos relativos à inadequação na estrutura física das unidades de saúde. Tais situações foram expressas nas falas de gestores, profissionais e mães como impeditivos para um cuidado eficaz, eficiente e resolutivo.

A ausência do encontro entre profissionais da mesma equipe de saúde foi revelada como fator limitador do cuidado à criança, pois compromete a complementaridade das ações de cuidado. São situações difíceis para as mães que vêem seus filhos submetidos a serviços pouco resolutivos e descomprometidos com a vida e com a dignidade humana. São condições que expõem as crianças a uma atenção fragmentada, desqualificada e injusta.

Frente às limitações físicas e estruturais da Atenção Básica e do sistema de saúde, as mães procuram outros meios para ter as necessidades dos seus filhos atendidas, preferencialmente, o atendimento hospitalar nos serviços de urgência. Nas falas dos participantes, a Estratégia Saúde da Família não tem conseguido resolver os problemas de saúde da criança, e a articulação das ações entre a atenção básica, a média e a alta complexidade acontece de forma informal caracterizado pelos participantes como "fluxo do amigo". A contra-referência é praticamente inexistente, e quando ocorre é pela articulação do enfermeiro diretamente com a família e não com o serviço onde foi realizada a atenção. São situações que ferem aos princípios de acesso, da equidade e da integralidade da atenção definidos no SUS.

Tais situações geram descrédito no sistema de cuidados em saúde, ruindo com os princípios da universalidade e da integralidade. Somam-se a este aspecto, o reconhecido estrangulamento no sistema de acesso aos demais níveis de atenção. A pouca eficácia, mais uma vez, determinam descrédito, desconfiança e insegurança na população e nos profissionais. Tais situações têm refletido o baixo impacto da ABS na saúde da criança, e tem sido explicada, de forma mais frequente, pela desarticulação entre os níveis de atenção produzindo um círculo vicioso: ABS com baixa resolutividade aumenta a demanda nos demais níveis de complexidade, e consequentemente, aumenta a insegurança da população em relação a ABS. É um circulo onde as dificuldades e limitações são produzidas e reproduzidas continuamente.

A integralidade como princípio doutrinário do SUS deve considerar as necessidades específicas das crianças inserindo-as em uma rede hierarquizada da atenção em saúde com níveis crescentes de complexidade dos serviços. Assim as ações de baixa, média e alta complexidade buscam articular-se para aumentar o nível de resolutividade e de sua capacidade no atendimento às de- 
mandas. Observamos tanto nas falas dos gestores como dos profissionais, a inexistência de uma rede articulada dos serviços de atenção à criança. O sistema de saúde não garante efetividade do sistema de referência e contra-referência, apresentando, portanto, problemas por não garantir continuidade do cuidado nos diversos níveis da atenção.

\section{REFERÊNCIAS}

1. Backes DS, Sousa FGM, Mello ALF, Erdmann AL, Nascimento KC, Lessmann JC. Concepções de cuidado: uma análise das teses apresentadas para um programa de pós-graduação em enfermagem. Texto Contexto Enferm. 2006; 15(Esp):71-8.

2. Schraiber LB, Pedduzzi M, Sala A, Nemes MIB, Castanhera ERL, Kon R . Planejamento, gestão e avaliação em saúde: identificando problemas. Ciênc Saúde Coletiva. [online]. 1999 [acesso 2008 Ago 07]; 4(2):221-42. Disponivel em: http://www. scielo.br/scielo.php?script=sci_arttex\&pid=S141381231999000200002\&Ing=pt

3. Strauss AL, Corbin J. Grounded Theory Methodology: an overview. In: Denzin NK, Lincoln YS. Handbook of quantitative research. Thousand Oaks (US): Sage Publications; 1994. p. 273-85.

4. Strauss AL, Corbin J. Pesquisa qualitativa: técnicas e procedimentos para o desenvolvimento de Teoria Fundamentada. Porto Alegre (RS): Artmed; 2008.
5. Sousa FGM. Tecendo a teia do cuidado à criança na Atenção Básica de Saúde: dos seus contornos ao encontro com a integralidade [tese]. Florianópolis (SC): Universidade Federal de Santa Catarina. Programa de Pós-Graduação em Enfermagem; 2008.

6. Trench MH, Peduzzi M. Trabalho em equipe e trabalho em grupo no PSF. Rev Bras Enferm. 2000; 53(Esp):143-7.

7. Ribeiro EM, Pires DEP, Blanck VLG. A teorização sobre o processo de trabalho em saúde como instrumental para a análise do trabalho no Programa Saúde da Família. Cad Saúde Pública. 2004 Mar-Abr; 20(2):438-46;

8. Ministério da Saúde (BR). DATASUS [página da internet]. Informações em saúde [acesso 2008 Jun 20]. Disponível em: http://www.datasus.gov.br

9. Sociedade Brasileira de Pediatria. O Programa Saúde da Família e a pediatria. SBP Notícia [página da internet]. 2004 Nov-Dez [acesso 2008 Ago 07]; 34:6-7. Disponível: http://www.sbp.com.br/show_item2. cfm?id_categoria $=88 \& i d \_d e t a l h e=1671 \&$ tipo_ detalhe $=\mathrm{s}$

10. Ministério da Saúde (BR). Secretaria de Atenção à Saúde. Departamento de Atenção Básica. Manual Técnico para estruturação física das Unidades Saúde da Família. Brasília (DF): Ministério da Saúde, 2004.

11. Bodstein R. Atenção Básica na Agenda da Saúde. Ciênc Saúde Coletiva. 2002; 7(3):401-12. 